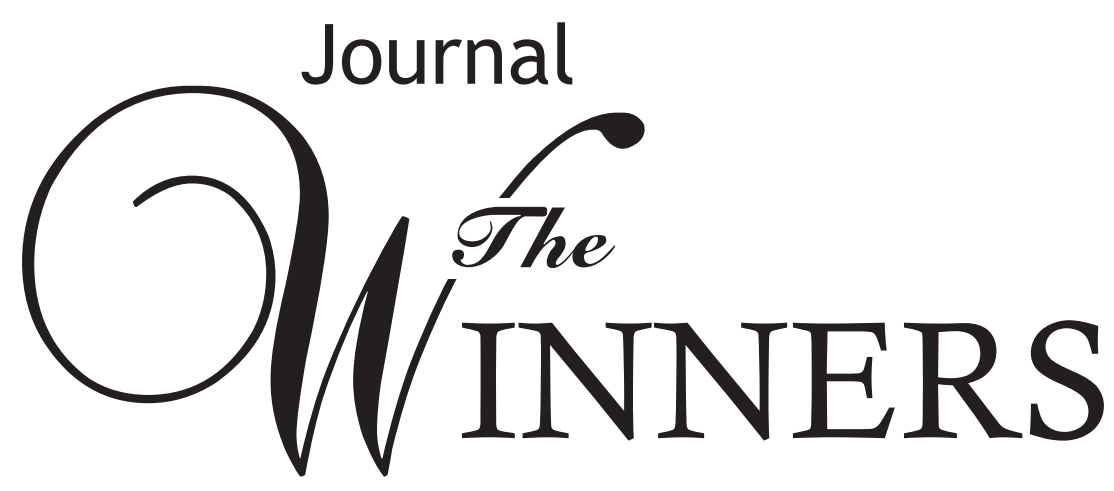

P-ISSN: 1412-1212

E-ISSN: 2541-2388

Economic, Business, Management, and Information System Journal

Vol. 20 No. 1 March 2019

\section{Editor in Chief}

Rudy Aryanto

\section{Managing Editors}

Arta Moro Sundjaja

Noerlina

\section{National Editor Board}

Engkos Ahmad Kuncoro

Idris Gautama So

Yasintha Soelasih

Levyda Levyda

Agus Zainul Arifin
Management Department, Bina Nusantara University, Indonesia

Information System Department, Bina Nusantara University, Indonesia Information System Department, Bina Nusantara University, Indonesia

\title{
Language and Layout Editor
}

Dina Nurfitria

Eka Yanti Pangputri

Atmawati

Holil

\section{Secretariat}

Haryo Sutanto

\begin{abstract}
Management Department, Bina Nusantara University, Indonesia Management Department, Bina Nusantara University, Indonesia Management Department, Atmajaya University, Indonesia Management Department, Sahid University, Indonesia

Management Department, Tarumanegara University, Indonesia
\end{abstract}

Bina Nusantara University, Indonesia

Bina Nusantara University, Indonesia Bina Nusantara University, Indonesia

Bina Nusantara University, Indonesia

Bina Nusantara University, Indonesia

\section{Description}

The Winners is a semiannual journal, published in March and September. The Winner focuses on various issues spanning in economics, business, management, and information system through this scientific journal. The Winners has been has been acreditied by DIKTI under the decree number 34/E/KPT/2018 (SINTA 3) and indexed by Academic Research Index (Research BIB), Directory of Open Access Journals (DOAJ), Microsoft Academic Search, Garda Rujukan Digital (Garuda); Bielefeld Academic Search Engine (BASE), World Catalogue (WorldCat) and Google Scholar, and Indonesian Research Repository (Neliti).

Research and Technology Transfer Office, Bina Nusantara University, Anggrek Campus, Jl.Kebon Jeruk Raya 27, Kebon Jeruk, Jakarta Barat 11530, Tel. +621-5350660 ext. 1705/1708, Fax.+621-5300244, E-mail: asundjaja@binus.edu, hsutanto@binus.edu, thewinner@binus.edu, http://journal.binus.ac.id/index.php/winners 


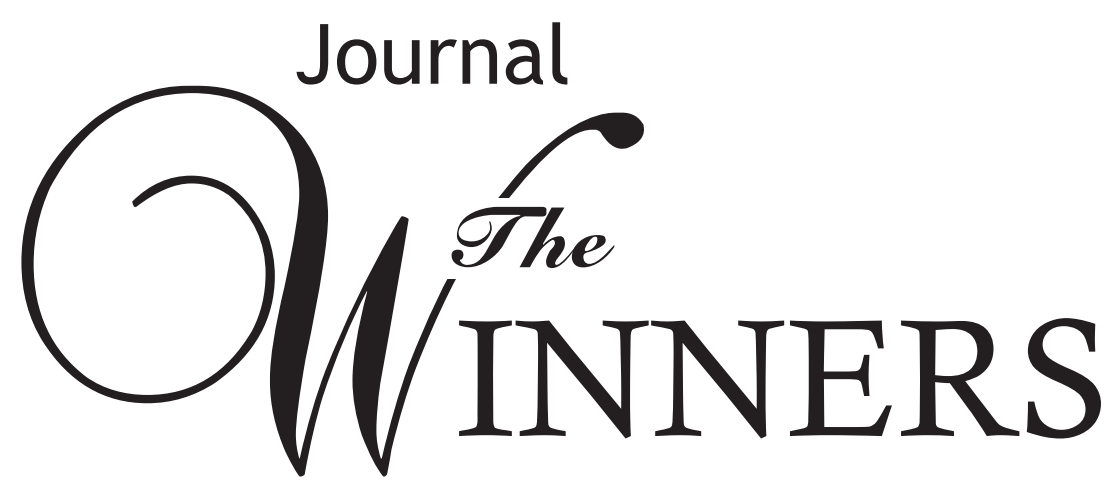

P-ISSN: $1412-1212$

E-ISSN: 2541-2388

Economic, Business, Management, and Information System Journal

Vol. 20 No. 1 March 2019

\section{CONTENTS}

Adi Teguh Suprapto; Mulyono; Danang Prihandoko

Price Fraction Changes Impact on Stock Trading Indicators: An Events Study on Indonesia Stock Exchange ....

Yulius Lie; Robertus Nugroho Perwiro Atmojo; Hery Harjono Muljo

The Effectiveness of $\mathrm{O} 2 \mathrm{O}$ Strategy on E-Commerce Transactions

Hermawan

Successful Implementation of Enterprise Resource Planning

Natasya; Elia Madatu Tandililing; Michael Angelus; Kevin

Tax E-Filing System Acceptance Level on the Taxation Compliance: An Application of the UTAUT Approach ...

Kevin Deniswara; Ratu Marwaah Firhatil Uyuun; Ang Swat Lin Lindawati; Willnaldo

Intellectual Capital Effect, Financial Performance, and Firm Value:

An Empirical Evidence from Real Estate Firm, in Indonesia 